Alina Liliana COZMA

Şcoala doctorală de ştiințe socio-umane

Universitatea „Dunărea de Jos” din Galați

\title{
LITERATURA ISANOSCIANĂ SUB SEMNUL RĂZBOIULUI
}

Magda Isanos vede lumina zilei pe 17 aprilie 1916, la Iași, cu puțin timp înainte ca România să intre în Primul Război Mondial, în timp ce Europa este stăpânită puternic de război. În toamna aceluiași an, statul român are parte de foarte multe înfrângeri, capitala României este acaparată de Falkenheim, iar emigrarea spre Iași este profundă, creionându-se un tablou teribil, ocupat de mii de refugiați, români și de alte origini.

Familia scriitoarei se retrage la Costiujeni, o localitate din apropierea Chișinăului, iar Magda Isanos își urmează studiile în Basarabia, devenind, mai târziu, o figură literară emblematică.

Războiul îi răpește primele creații, care rămân în casa de la Costiujeni, în anul 1940, când familia autoarei fuge din Basarabia. Alte manuscrise se pierd din cauza exploziei unei bombe în curtea casei. Altfel spus, războiul își însușește, pe nedrept, câteva „piese de puzzle” care conturează portretul literar al Magdei Isanos.

În Basarabia, creația izvorăște din amarul sufletului, este scrisă cu un toc îmbibat în lacrimi, iar slovele poartă toată nostalgia și emoția creatorului:

„Literatura basarabeană s-a scris, astfel, cu vaietul înfundat al suferinței, cu lacrima tremurândă a înstrăinării, cu sângele picurat de pe cuiele răstignirii, cu geamătul surd al «jalei nestinsului dor», cu duhul strămoșilor reînviat din mormintele trecutului dacic sau voievodal, cu respirația fierbinte a însăși istoriei." [1]

Chișinăul constituie o imagine dezolantă, în care se simt pulsațiile accelerate ale inimilor locuitorilor, agitaţia dominând totul. Oamenii sunt debusolați, nevoiți să fugă, fără speranța că se vor mai întoarce, lăsând în urmă obiecte și amintiri de preț:

"Chișinăul părea un furnicar stârnit: ofițerii își împachetau lucrurile și își trimiteau familiile dincolo de Prut, zvonurile circulau, se crease panică; (...) Era 27 iunie 1940. Familia Isanos stătea la masă, când a sunat telefonul: «Ştii că s-a cedat Basarabia?» Vocea vestitoare era a Elenei Alistar. (...) Ordinul de evacuare fusese transmis de la Prefectura Lăpuşna la ora 12 și 15, către primăriile din județ: «Conform ordinului Marelui Stat Major NO.6100 din 28 
Iunie 1940 astăzi începe evacuarea Basarabiei aplicând întocmai planul Tudor. Astăzi, cu trenul cât și pe jos, ofițerii și funcționarii vor lua numai strictul necesar (bagaje). Nu se admite mobilier. Comunicați prezentul ordin la toate administrațiile din raza județului. Evacuarea Chișinăului și a Basarabiei până la ora 18»".[2]

Se pare că, în această situație, timpul nu mai are răbdare, silind persoanele să-și părăsească, involuntar, viața pe care au trăit-o până la acest moment. În capitala Moldovei este valvă, auzindu-se zgomotele asurzitoare ale tancurilor și ale tunurilor, în timp ce ultimul tren se îndreaptă spre România, iar rușii cotropesc orașul. Mihai Isanos, tatăl autoarei, merge la spital să predea cheile, apoi se îndreaptă către gară. În România, familia Magdei Isanos locuiește vreme de o lună în casa din Iași a scriitoarei. Casa părintească îi provoacă un dor imens şi doar scriind îşi poate potoli această stare sufletească: „Pentru că anul 1940, începând din iunie, a stat sub semnul sfâșierii, Magda avea în ea dorul de provincia ireversibilă" [3]. Este dureros că multe dintre manuscrise rămân în Basarabia, poeta fiind silită să parcurgă, parcă, un drum sisific. De altfel, nu doar crunta soartă, ci și sistemul politic existent nu îi permite să se afirme în plan literar așa cum merită. Imaginea casei și a grădinii, pe care Magda Isanos le evocă deseori în poeziile sale, este degradată în realitate, căci, din locuințele oamenilor nu mai rămâne nimic în Chişinău. Totul este distrus într-un an, începând de la case, catedrală, mitropolie, primărie, Sală eparhială și continuând cu tipografiile, băncile, fabricile, depozitele, liceele etc. S-ar crede că se dorește a se șterge orice urmă a lui Dumnezeu pe pământ, prin incendierea bisericilor, însă El dăinuiește în elementele naturii, așa cum notează Magda Isanos în versurile ei:

„În vremea asta, Dumnezeu zbura-n copaci,/ făcându-i să înflorească. (...) Era când câmpie verde, când apă./ Alteori se făcea mic/ și s-ascundea în floarea de finic,/ ori s-apuca să crească-n păpușoaie (Dumnezeu)"..[4]

În anul 1941, după după o perioadă de câteva luni, în care fuseseră asasinate masive, Magda Isanos se întoarce în Costiujeni, fiind decepționată de imaginea pe care o zărește aici. Este determinată, așadar, să scrie poezii despre realitatea cruntă. Notațiile ei pe seama războiului sunt realizate dintr-o perspectivă obiectivă, vorbind despre sărăcia care domină satele, despre soldații morți, despre efectele războiului, fiind acuzată de comunism, din cauza ilustrării adevărului. Răspunsul scriitoarei la acuzele primite este, după cum obișnuiește, foarte sincer: 
„Dacă a scrie despre foamea familiilor sărace cu bărbații plecați la război, despre atrocitățile comise, înseamnă că am astfel de tendințe, nu aveti decât să mă considerați așa, când eu nu fac decat sa iau apărarea celor care suferă". [5].

Magda Isanos își găsește salvarea în lirică, strigându-și rugăciunea în rime. Se roagă pentru pace, pentru pâine și pentru somn, își dorește liniște pentru ea și pentru ceilalți:

„Înger din lumină, roagă-te pentru mine,/ ieși din casa ta zidită-n rază/ și zi: «Doamne, mă rog pentru pâine, pentru somn și liniște-n amiază»". (Înger din lumină). [6]

Dintr-atâta amar, ea găsește lumina și cere pâine și somn. Solicită, de fapt, coborârea lui Dumnezeu peste tot ținutul, șansa de a gusta din trupul Lui și tihna primordială.

Al doilea refugiu pe care îl face autoarea este cel din anul 1944, în ultimul ei an din viață, fiind bolnavă și transportată, din această cauză, cu mare dificultate. Oamenii sunt cuprinși, din nou, de panică, iar orașele sunt devastate:

„Pe un acoperiș de casă aterizase un vagon de tramvai, peste tot - morți înșirați pe străzi, mai ales copii, acoperiți cu ziare. Așa arăta centrul Bucureștiului după bombardamentul american de la 4 aprilie 1944". [7]

Aceasta, împreună cu membrii familiei, se retrage în Argeș, în comuna Drăganu. Locuiesc într-o casă închiriată, care dispune de o grădină minunată ce-i amintește tinerei scriitoare de plaiurile unde şi-a petrecut copilăria. Într-un manuscris de la Drăganu, unul dintre puținele care au rezistat, sunt chiar versuri semnate de Magda Isanos:

„Plină de bucurie m-am deșteptat: Mai am o zi. (12 iunie 1944, Drăganu Argeș) Ca și cum ar fi primit în dar ce alții consideră de la sine înțeles și cuvenit: o zi de viață". [8]

Ecoul războiului răsună în literatura isanosciană, mai ales, datorită temelor pe care tânăra scriitoare le abordează: moartea, lupta pentru viață, timpul, călătoria pusă sub masca refugiului, dragostea prea puțin împlinită, căci soțul ei, Eusebiu Camilar, se află pe front.

Autoarea reliefează în multe dintre operele sale efectele războiului și dorința asiduă de împăcare. De pildă, în poezia Iartă-mă, frate, poeta se adresează tuturor oamenilor, poporului, chiar prin substantivul în cazul vocativ, la genul singular, frate, care este utilizat cu sens colectiv. Aceasta își dorește să făurească un secol în care să domnească dragostea de frate, căci au același Tată: 
„Iartă-mă pentru urile strămoșeşti./ Vrei peste sânge-n casă să pășeşti,/ sămpărțim prânzul sărac,/ să vorbim despre noul veac/ al dragostei dintre oameni? /Fratele meu, ce bine te-asameni/ cu mine! Născuți din pământ, am fost purtați de-un potrivnic vânt/ între drapele și săbii." [9]

Printr-o deosebită putere creatoare și încărcată cu un optimism infinit, Magda Isanos primește cu bucurie tot ce i se întâmplă. De pildă, în refugiul din Argeș, în 1944, când este cărată pe brațe din cauza bolii ei, aceasta zâmbește pentru a alina tristețea celor care o văd în suferință.

Mihai Cimpoi aseamănă literatura basarabeană cu Biblioteca din Alexandria, susținând, în mod drept, următoarele:

„Cum ai putea să investighezi și să valorifici întregul ei fond de cărți, manuscrise, publicații, mărturisiri epistolare când o parte bună din ele au fost arse, nimicite, cenzurate, arestate, bombardate, ascunse în tainițe, dosite după alte cărți sau predate securității?"[10]

Este adevărat și, în același timp, foarte trist că unii autori sunt îngropați în anonimat, din cauza factorilor politici. Iar dacă unora soarta le mai dă o șansă, în cazul Magdei Isanos nu este așa, căci moartea îi îmbrățișează trupul prea devreme. Aprecierile remarcabile vin, mai ales, după dispariția autoarei.

Magda Isanos întruchipează omul exilat, care se agaţă de orice clipă, trăind-o la intensitate maximă și așezând-o în cuvinte.

Criticul literar Mihai Cimpoi descrie într-un mod artistic, dar, mai ales, real, poezia fiicei Basarabiei:

„Poezia Magdei Isanos, datorită și indiscutabilei dimensiuni basarabene a vizionarismului ei social, e o poezie de început de secol cu fâlfâiri agitate de drapele și aprinderi de sfeșnice, cu strigăte de groază și sunete chemătoare de goarne, cu mâini întinse peste ruine şi morminte, cu incendieri de zări, cu galopări tropotitoare și cu suliți ridicate la ceruri, cu oameni porniți, «după pilda șuvoaielor revărsate»". [11]

Scriitorul basarabean, în genere, ilustrează destinul unui individ tragic prin asumarea înstrăinării, pusă sub pecetea terorii istoriei.

NOTE:

[1]. Mihai Cimpoi, O istorie deschisă a literaturii române din Basarabia, Editura Arc, Chișinău, 1997, p.12.

[2].Elisabeta Isanos-Botez. Veronica Isanos-Luscalu, Ana Isanos, „Memorii” în Elisabeta Isanos, Cosânzenii, Editura ArtPress, București, 2005, p.165.

[3]. Ibidem, p.166. 
[4].Magda Isanos, Scrieri, ediție, studiu introductiv, repere cronologice, note și comentarii, referințe bibliografice de Aliona Grati, Editura Știința, Chișinău, 2016, p.85.

[5]. Ibidem, p. 182.

[6]. Ibidem, p.59.

[7]. Ibidem, p.219.

[8]. Ibidem, p. 223.

[9]. Ibidem, p.87.

[10]. Mihai Cimpoi, op. cit., p.14.

[11]. Ibidem, p.133.

\section{BIBLIOGRAFIE:}

Antofi, Simona, GENERAL DICTIONARY OF ROMANIAN LITERATURE OBVERSE AND REVERSE CRITICAL RECEPTION, în Oana Cenac (coord., edit.), International Conference of Common Vocabulary/Specialized Vocabulary: Manifestations of Creativity of Human Language, 6-7 iunie 2014, publicate în volumul MANIFESTARI ALE CREATIVITATII LIMBAJULUI UMAN, 2014, p. 13-19, Accession Number WOS:000378446400001.

Antofi, Simona, Contemporary Critical Approaches to the Romanian Political and Cultural Ideology of the XIXth Century - Adrian Marino, Al treilea discurs. Cultura, ideologie si politica in Romania / The Third Discourse. Culture, Ideology and Politics in Romania, în Antofi, S., Ioana N., Necula, G., Ifrim, N., Crihană, A., (edit.), Procedia Social and Behavioral Sciences, 4th International Conference on Paradigms of the Ideological Discourse - The Dynamics of Terminologies and (Re)Shaping of Ideologies, 2012, p. 22-28, DOI: 10.1016/j.sbspro.2012.10.005, Galati, ROMANIA, 31 mai - 1 iunie 2012, Accession Number WOS:000361477200004

Cenac, Oana, Discurs ideologic în "Ateneu" 1965, Actele conferinței internaționale Lexic comun / Lexic specializat. Democratizarea cunoașterii" sau migrația lexicului specializat spre lexicul comun, ediția a X-a, Universitatea „Dunărea de Jos" din Galați, Facultatea de Litere, Centrul de Cercetare Comunicare interculturală și literatură, 19 - 20 mai 2017, publicată în Analele Universității „Dunărea de Jos” din Galați, Fascicula XXIV Lexic comun / lexic specializat, revistă indexată in bazele de date internaționale EBSCO: https://www.ebscohost.com/titleLists/cms-coverage.pdf, MLA (Modern Language Association, New York, www.mla.org) - MLA International Bibliography $\mathcal{E}$ Directory of Periodicals, CEEOL și Fabula. La recherche en littérature (www.fabula.org), anul X, nr. 2(18) /2017, Editura Casa Cărții de Ştiință, Cluj-Napoca, 2017, ISSN 1844-9476, p. 31-48.

Cimpoi, Mihai, Basarabia sub steaua exilului, Editura Viitorul românesc, București, 1994. 
Cimpoi, Mihai, O istorie deschisă a literaturii române din Basarabia, Editura Arc, Chișinău, 1997.

Ciobanu, Ștefan, Cultura românească în Basarabia sub stăpânirea rusă, Editura Enciclopedică „Gheorghe Asachi”, Chișinău, 1992.

Elisabeta Isanos, Cosânzenii, Editura ArtPress, București, 2005.

Ifrim, Nicoleta, History and Identity in Post-Totalitarian Memoir Writing in Romanian,

CLCWeb: Comparative Literature and Culture (ISSN 1481-4374) http://docs.lib.purdue.edu/clcweb/, nr. 16.1 / March 2014, Purdue University Press, revistă indexată ISI Art and Humanities Citation Index http://docs.lib.purdue.edu/clcweb/vol16/iss1/11/, Accession Number WOS:000333326200011.

Ifrim, Nicoleta, Theoretical Aspects of Identity Discourse in Post-totalitarian Cultures, Conferința Internațională Paradigma discursului ideologic (PID 4), 31 mai1 iunie 2012, Facultatea de Litere, Galați, în Procedia-Social and Behavioral Journal (ISSN: 1877-0428) (ISSN: 1877-0509), vol.63/2012 ELSEVIER (www.elsevier.com) indexată ScienceDirect, Scopus, Thomson Reuters Conference Proceedings Citation Index (ISI Web of Science), pp.35-40, DOI 10.1016/j.sbspro.2012.10.007,

http:/ / www.sciencedirect.com/science/journal/18770428/63/supp/C, WOS:000361477200006 (indexare ISI)

Isanos, Magda, Scrieri, Ediție, studiu introductiv, repere cronologice, note și comentarii, referințe bibliografice de Aliona Grati, Editura Știința, Chișinău, 2016.

Piru, Alexandru, Istoria literaturii române, Editura Grai şi Suflet, Bucureşti, 1994. Rotaru, Ion, O istorie a literaturii române, vol.III, Editura Minerva, Bucureşti, 1987.

\section{Isanosian Literature under the Sign of War}

Abstract: Magda Isanos was born on April 17, 1916, in Iasi, shortly before Romania entered the First World War, while Europe is strongly ruled by warriors. In the autumn of the same year, the capital of Romania is taken over by Falkenheim, and the emigration to Iasi is profound, drawing a terrible painting, occupied by thousands of refugees, Romanians and other origins. The writer's family retires to Costiujeni, a village near Chisinau and Magda Isanos follows her studies in Bessarabia, later becoming an emblematic literary figure. The war takes away her first creations, which remain in the house from Costiujeni, in 1940, when the author's family flees from Bessarabia. Other manuscripts are lost due to the explosion of a bomb in the yard. In other words, the war misappropriates a few "puzzle pieces" that build the portrait of Magda Isanos. The echo of the war resounds in isanosian literature, especially because of the themes the young writer approaches: death, the struggle for life, time, the journey under the guise of the refuge, the love that is too little fulfilled, because her husband, Eusebiu Camilar, is on the front. With an incredible creative power and loaded with infinite optimism, 
Magda Isanos gladly receives everything that is happening to her. For example, in the refuge in Arges, in 1944, when she is carried on arms, because of her illness, she smiles to relieve the sadness of those who see her in distress. However, her notations about the war are made from an objective perspective, talking about poverty that dominates villages, about dead soldiers, about the effects of the war, being accused of communism, because of the illustration of the truth.

Keywords: war, refuge, creation. 